\title{
ORAL ADMINISTRATION OF ZOLPIDEM TARTRATE IN AN ABUSE-DETERRENT FORMULATION VERSUS AN IMMEDIATE RELEASE FORMULATION IN BEAGLE DOGS
}

\author{
Amina Vazda, Wei Xia and Håkan Engqvist* \\ Division of Materials Science, Department of Engineering Sciences, The Ångström Laboratory, Uppsala University, 75121 Uppsala, Sweden \\ *Corresponding author E-mail address: hakan.engqvist@angstrom.uu.se
}

Accepted: 10 August 2021

Published: 19 October 2021

DOI:10.2340/scandjms.v1.41

Objective: The continuing rise of prescription drug abuse has greatly necessitated the development of an abuse-deterrent formulation. Geopolymers are a promising base for drug design as they allow for tuneable drug release and possess superior physical and chemical properties compared with conventional pharmaceutical excipients.

Methods: Geopolymer pellets containing zolpidem tartrate were administrated orally to beagle dogs as a controlled-release formulation with the commercial immediate-release product, Stilnoct tablets, as the control.

Results: The administration of zolpidem tartrate as immediaterelease tablets demonstrated an elevated immediate release plasma profile and the zolpidem tartrate in the geopolymers demonstrated a controlled-release plasma profile. The pharmacokinetic analysis demonstrated that immediate-release tablet administration generated much higher plasma concentration when compared with geopolymer pellets administration for zolpidem tartrate. On the other hand, the geopolymer formulation prolonged the time of drug release.

Conclusion: Oral administration of zolpidem tartrate in geopolymer pellets demonstrated a controlled-release plasma profile.

Key words: In vivo; zolpidem; abuse-deterrent formulation; HPLC.

O pioids are narcotic analgesics that bind to the receptors in the central and peripheral nervous systems and are frequently used for the treatment of chronic pain - and as pain relief in cancer conditions (1). With the increase in opioid consumption, concern has been expressed on the escalating misuse and non-medical use of prescription opioids, which has resulted in increased deaths by overdose. The Center for Behavioural Health reported, in their 2015 National Survey on Drug Use and Health, that approximately 2 million people are misusing opioids and it is now considered a public health issue in the USA (2). In the USA, 63,632 persons died of an overdose in 2016 and $66.4 \%$ of the cases involved an opioid, while in 2017, the number increased to 70,237 where $67.8 \%$ involved opioids $(3,4)$. The Food and Drug Administration (FDA) strongly recommended an assessment regarding the abuse potential to all opioid products (5). Controlled-release drug products

\section{LAY ABSTRACT}

The increase of abuse of prescription drugs has shown the necessity for an abuse-deterrent formulation (ADF). Geopolymers have been designed as an ADF by adding physical and chemical barriers making them more difficult to abuse. In this study, we studied the oral administration of zolpidem tartrate in geopolymer pellets in dogs. The control group was a commercial product (Stilnoct ${ }^{\circ}$ tablets), which give an immediate release compared with the geopolymer, which is a controlled-release drug, i.e. longer time to release the drug. The results showed a controlledrelease of the geopolymer, while Stilnoct demonstrated an elevated immediate release. However, the amount of drug detected in the plasma was significantly lower for the geopolymer formulation when compared with the control group. Finally, no adverse signs were seen in the dogs after oral administration of the two different test items.

are particularly attractive targets for abuse as they contain larger drug doses than their corresponding immediate-release counterparts.

The addition of physical and chemical barriers is the most efficient and useful method to prevent drug abuse in abusedeterrent formulations (6). Physical destruction of the matrix and extraction with a solvent are two common ways of obtaining higher doses from opioid oral tablets, which has led to the development of rigid structures and insoluble coatings (5). Currently, eight commercial abuse-deterrent formulations are approved by the FDA (7). These formulations are polymer-based tablets and new efforts are now focused on how to make the matrix rigid against extraction, crushing and gelling $(6,7)$.

Compared with the polymer-based matrix, a ceramic-based matrix provides a stronger physical barrier. Medications, from small molecule drugs to biopharmaceuticals, have been loaded into ceramic matrices for treating different diseases 
$(8,9)$. Geopolymers have been developed as a ceramic-based matrix for an abuse-deterrent formulation with controlled drug release and low abuse ability, as shown in our previous studies (10). In those studies, the geopolymer showed high mechanical strength when subjected to crushing, and low amounts of drug were extracted with solvents such as $40 \%$ ethanol (10). Geopolymers are often referred to as inorganic polymers with the basic unit of polysialates, containing $\mathrm{SiO}_{4}$ and $\mathrm{AlO}_{4}$ tetrahedra. Depending on the different compositions and synthesis conditions, geopolymers can exhibit various physical and chemical properties, such as high mechanical strength, low porosity and low solubility (11).

The leach out of aluminium from the geopolymer matrix could potentially be harmful in the long-term, since exposure to a high level of aluminium can cause damage to the reproductive and nervous system (12). The release of aluminium from a geopolymer has previously been assessed, where the release of aluminium has been collected up to $24 \mathrm{~h}$ in both $\mathrm{pH} 1$ and $\mathrm{pH}$ 6.8 (13). The findings showed that the aluminium leached after $24 \mathrm{~h}$ but was still significantly lower than the non-observedadverse-effect levels (1 mg aluminium/kg bw/week) issued by the European Food Safety Authority (14).

To the best of the authors' knowledge, geopolymers have not previously been tested in vivo as an oral formulation. However, geopolymers containing tricalcium phosphate and hydroxyapatite have previously been evaluated in vivo as a bone filling material showing that geopolymers are highly biocompatible and no significant leakage of aluminium was detected after 1 month of implantation $(15,16)$.

Drug release of fentanyl and zolpidem from a geopolymer has been compared in a previous study (17), which showed that the two drugs had similar physicochemical properties (Table I). Due to safety reasons, in this study, zolpidem was used as a model substance for Fentanyl, since it is less potent. The aim of this study was to evaluate the plasma profiles and the pharmacokinetic parameters following oral administration of zolpidem tartrate in geopolymer pellets aiming for controlledrelease, in comparison to a commercial immediate-release tablet formulations in dogs. The immediate-release formulation was chosen according to FDA guidelines, which state that immediate-release formulations are a valid comparator to controlled release formulations (6). In addition, abuse-deterrent properties of both geopolymer and Stilnoct ${ }^{\circledR}$ were investigated according to the FDA's guidelines in three common media; $70^{\circ} \mathrm{C}$, $40 \%$ ethanol and $\mathrm{pH} 1$.

\section{MATERIALS AND METHODS}

\section{Materials}

Kaolin, fumed silica, sodium hydroxide, monopotassium phosphate and 37\% fuming hydrochloric acid was purchased from Sigma Aldrich (Sweden). Zolpidem tartrate from Cambrex $A B$ (USA). Eudragit L100-55 was purchased from Evonik (Germany). Stilnoct ${ }^{\circledR}$ tablets were purchased from Sanofi $A B$ (Stockholm, Sweden). Capsules (Coni-shaped, size 0) were purchased from Capsugel (Sweden).

\section{Pellets Manufacture/Geopolymer Synthesis}

By thermally treating Kaolin at $800^{\circ} \mathrm{C}$ for $2 \mathrm{~h}$, 'metakaolin' was formed. A waterglass was made by mixing fumed silica and sodium hydroxide with water, into a homogenous and clear fluid. The waterglass was then mixed with metakaolin, Eudragit L10055 ( $1 \mathrm{~g}$ per $6.5 \mathrm{~g}$ of metakaolin) and zolpidem ( $1 \mathrm{w} / \mathrm{w} \%$ ) to form a geopolymer paste. Eudragit L100-55 is a copolymer that starts dissolving above a $\mathrm{pH}$ of 5.5, i.e. it protects the geopolymer under acidic conditions. The geopolymer paste was moulded by hand into $1.5 \mathrm{~mm} \times 1.5 \mathrm{~mm}$ Teflon moulds. After curing the pellets (48 h, 100\% RH) were packed into capsules (Fig. 1). The manufactured pellets consisted of the following molar ratios: $\mathrm{Si} /$ Al:1.94, $\mathrm{H}_{2} \mathrm{O} / \mathrm{Al}_{2} \mathrm{O}_{3}: 12.24$ and $\mathrm{Na}_{2} \mathrm{O} / \mathrm{Al}_{2} \mathrm{O}_{3}: 1.23$.

The final assay analysis demonstrated a total amount of $6 \mathrm{mg}$ of zolpidem per manufactured capsule after packaging.

\section{Preparation of Stilnoct ${ }^{\circledR}$ Tablets}

Each Stilnoct ${ }^{\circledR}$ tablet was packed into a capsule to match those of the pellets.

\section{Characterization of the Geopolymer}

The morphology of the geopolymer was studied with Scanning Electron Microscopy (SEM; Zeiss Leo 1550, operated at 3 kV). The pellets were attached to carbon tape and coated with PtAu to avoid charging. The phase composition was determined by X-ray diffraction (XRD; Bruker, D8 Advanced) by using CuKa $(\lambda=1.5418 \AA)$.

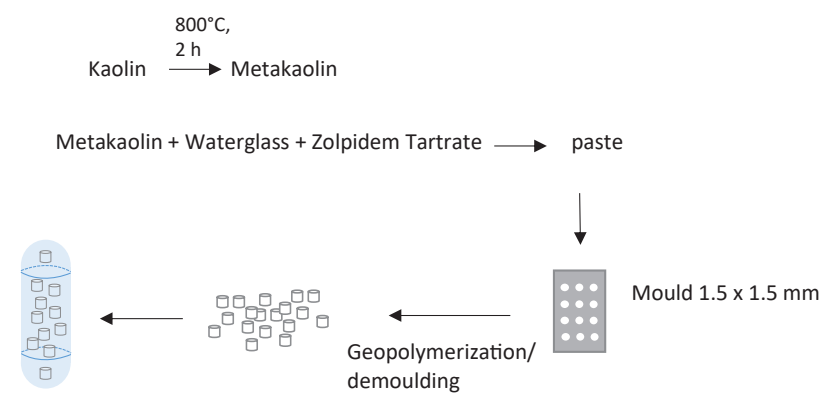

Fig. 1. Illustration of procedure for manufacturing and packing geopolymer pellets.

Table I. Physicochemical properties for fentanyl citrate and zolpidem tartrate $(18,19)$

\begin{tabular}{lll} 
& Zolpidem tartrate & Fentanyl citrate \\
Molecular weight $(\mathrm{g} / \mathrm{mol})$ & 457.483 & 528.602 \\
Solubility in water & $23 \mathrm{mg} / \mathrm{mL}$ & $25 / \mathrm{mL}$ \\
pKa & 6.2 & 8.4 \\
Log P & 1.2 & 2.98 \\
Topological polar surface area $\left(\AA^{2}\right)$ & 153 & 156 \\
\hline
\end{tabular}




\section{Abuse-deterrent Properties of the Test Items}

Both Stilnoct ${ }^{\circledR}$ tablets and geopolymer pellets were investigated for abuse-deterrent properties according to FDA guidelines in three household solvents in non-sink conditions; $\mathrm{pH} 1,40 \%$ ethanol and $70^{\circ} \mathrm{C}$ water (5). The three different media were chosen to mimic commonly used abuse methods; $\mathrm{pH} 1$ for cleaning supplies, $40 \%$ ethanol for alcoholic beverages and $70^{\circ} \mathrm{C}$ water for tea. The same method was applied to $\mathrm{pH} 1$ and $40 \%$ ethanol; $500 \mathrm{mg}$ of pellets was added to $10 \mathrm{~mL}$ of media with a stirring rate of about $50 \mathrm{rpm}$. Samples $(1 \mathrm{~mL})$ were taken out after 5, 30 and $60 \mathrm{~min}$. Due to the fast evaporation of water at $70^{\circ} \mathrm{C}, 500 \mathrm{mg}$ of pellets were added to a larger volume $(50$ $\mathrm{mL}$ ) of $70^{\circ} \mathrm{C}$ water with a stirring rate of about $50 \mathrm{rpm}$. Samples were taken out after $5 \mathrm{~min}$ and $30 \mathrm{~min}$. All geopolymer samples were filtered with $0.2 \mu \mathrm{m}$ millipore and analysed with a UVspectrophotometer at $241 \mathrm{~nm}$, while the Stilnoct ${ }^{\circledR}$ tablets were analysed with HPLC due to high background noise from the tablet matrix.

\section{In Vitro Drug Release of Zolpidem from Test Items}

An in vitro characterization was done prior to the start of the in vivo test to simulate gastric and intestinal $\mathrm{pH}$. The characterization was done in sink conditions by using a USP ॥ dissolution bath to measure drug release $f$ rom both Stilnoct ${ }^{\circledR}$ tablets in capsules and geopolymer pellets in capsules, over time in two different media: a phosphate buffer $(\mathrm{pH} 6.8)$ and $0.1 \mathrm{M} \mathrm{HCl}(\mathrm{pH} 1)$, which simulated the condition in the intestine tract and stomach, respectively. The volume of the dissolution bath was $400 \mathrm{~mL}$, the temperature was set to $37^{\circ} \mathrm{C}$ and the paddle rate at $50 \mathrm{rpm}$. Samples were collected up to $24 \mathrm{~h}$; each sample $(n=3)$ was filtered with $0.2 \mu \mathrm{m}$ millipore and analysed using a UV-spectrophotometer at $241 \mathrm{~nm}$.

\section{In Vivo Study - Plasma Profile of Zolpidem after Oral}

\section{Administration to Dogs}

The in vivo study was performed on beagle dogs by the test facility SPM Biocameltec (Sidi Bou Othmane, Morocco) and was approved by the local Animal Care Veterinary Procedure in accordance with animal care guidelines. The study was also based on the OECD principles of Good Laboratory Practice ENV/ MC/CHEM(98)17. The study consisted of two groups with four animals in each (Table II). The dogs were fasted for $12 \mathrm{~h}$ prior to dosing. One group were given a Stilnoct ${ }^{\circledR}$ tablet in a capsule ( $5 \mathrm{mg}$ of zolpidem tartrate) and the other group were given the encapsulated pellets ( $6 \mathrm{mg}$ zolpidem tartrate). The difference in the administered doses was not compensated for in the plasma release profiles due to the low in vitro drug release from the geopolymer pellets. Body weight was measured before dosing and $24 \mathrm{~h}$ after the first dosing. the administration of the capsules was done by a veterinarian who put the capsule in the back of each dog's throat. Blood samples were collected at the following time points after administration: $t=0,0.5,1,2,3,4,6$, 9,12 and $24 \mathrm{~h}$. Daily clinical observations were made to detect sedative effects, mortality and morbidity.

\section{Analytical Method and Statistics}

Blood samples were centrifuged for plasma separation. A total of $50 \mu \mathrm{L}$ of the plasma was added to $450 \mu \mathrm{L}$ of $\mathrm{CH}_{3} \mathrm{CN}+$ Internal standard (zopiclone, $200 \mathrm{nM}$ ). The mixture was vortexed and centrifuged. The supernatant was analysed on an LC/MS-MS system and Acquity BEH C18 column (2.1 mm ID × 50 mm, 1.7 $\mu \mathrm{m})$.

The statistics were performed by calculating the average for each parameter and the standard deviation.

\section{RESULTS}

\section{Characterization of the Geopolymer}

The morphology of the geopolymer was studied with both SEM and XRD. The analysis with SEM showed a dense surface (Fig. 2). Furthermore, small cracks were formed when the sample was exposed to the vacuum in the microscope.

After hardening, the geopolymer showed an amorphous structure (Fig. 3). The two peaks $\left({ }^{*}\right)$ at 21.1 and 27.1 degrees indicate that there is still some unreacted Metakaolin present in the geopolymer.

\section{Abuse Deterrent Properties of the Test Items}

The geopolymer pellets demonstrated similar levels of extraction at $\mathrm{pH} 1$ and in $40 \%$ ethanol (Fig. 4). After 1 h, $8-10 \%$ of zolpidem was released in $\mathrm{pH} 1$ and $40 \%$ ethanol, while almost $50 \%$ was released after $30 \mathrm{~min}$ in $70^{\circ} \mathrm{C}$ water. All pellets were intact after the tests were terminated.

All of the drug was released from Stilnoct ${ }^{\circledR}$ tablets within $1 \mathrm{~h}$ in $\mathrm{pH} 1$ and within $30 \mathrm{~min}$ in $70^{\circ} \mathrm{C}$ water (Fig. 5). The tablets were completely dissolved within $30 \mathrm{~min}$ in both $\mathrm{pH} 1$ and $70^{\circ} \mathrm{C}$ water. In $40 \%$ ethanol, the tablets were intact in the first $10 \mathrm{~min}$, which

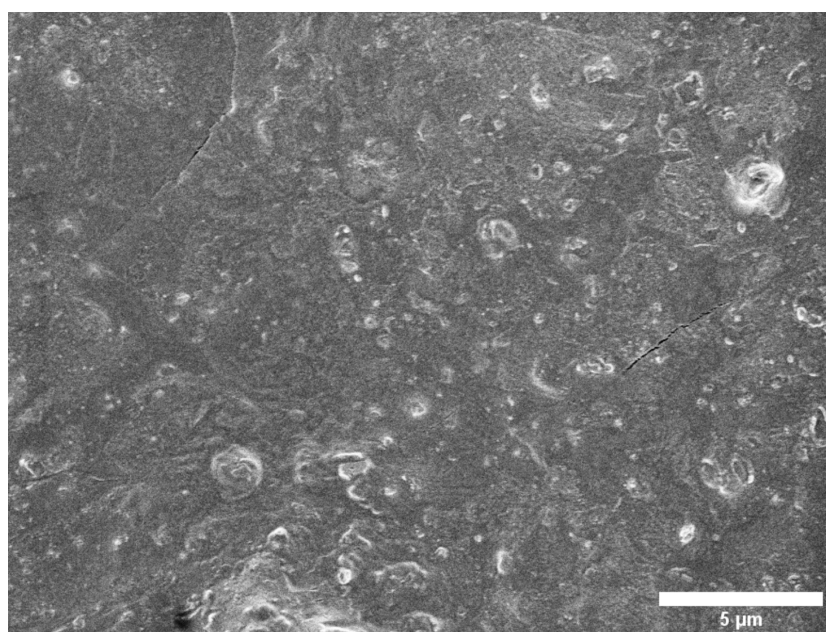

Fig. 2. Scanning electron microscope (SEM) image of the geopolymer surface.

Table II. Groups tested in the in vivo study

\begin{tabular}{lllll}
\hline Group no. & $n$ & Treatment & Dose per dog (mg) \\
1 & 4 & Dose A: Stilnoct $\Re$ tablets in a capsule containing 5 mg zolpidem & 5 \\
2 & 4 & Dose B: Geopolymer pellets in a capsule containing 6 mg zolpidem & 6 & 6
\end{tabular}




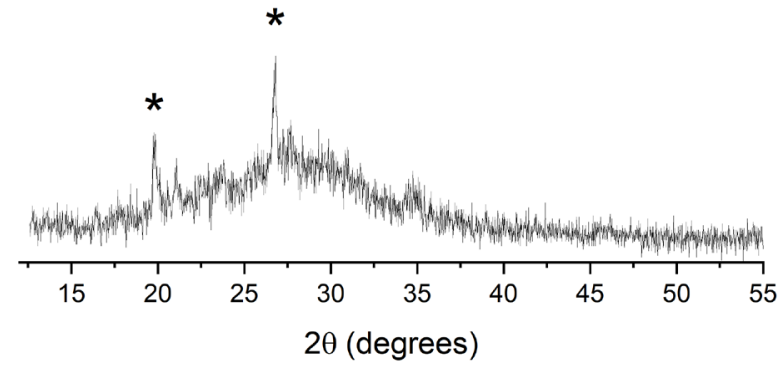

Fig. 3. Diffraction pattern of geopolymer with two peaks $\left(^{*}\right)$ indicating unreacted metakaolin.

can explain the low release in $5 \mathrm{~min}$. The slow disintegration of the tablet led to the slower release of zolpidem, which resulted in $80 \%$ release after $1 \mathrm{~h}$.

\section{In Vitro Release of Zolpidem from Stilnoct ${ }^{\circledR}$ Tablets and}

\section{Geopolymer Pellets}

The in vitro release of the drug from Stilnoct ${ }^{\circledR}$ tablets showed an immediate release profile. Almost all of the drug was released in both gastric $\mathrm{pH} 1$ and intestinal pH 6.8 within 30 min (Fig. 6A). After $24 \mathrm{~h}, 75 \%$ of the zolpidem in geopolymer pellets was released in $\mathrm{pH} 1$ and $50 \%$ in $\mathrm{pH} 6.8$ (Fig. 6B).

\section{In Vivo Plasma Profile of Zolpidem after Oral Administration of}

\section{the Test Items to Dogs}

In group 1, one of the four tested dogs in the immediate release formulation had zero levels throughout the study (Fig. 7A). The zolpidem concentration in plasma reached the top $\left(C_{\max }=17.4\right.$ $\mathrm{ng} / \mathrm{mL}$ ) and went back to the lower limit of quantitation (LLOQ) after 12 h. In group 2, only two of the four dogs had zolpidem levels above LLOQ in plasma following acute pellet administration (Fig. 7B). The other two exhibited low concentrations in plasma.

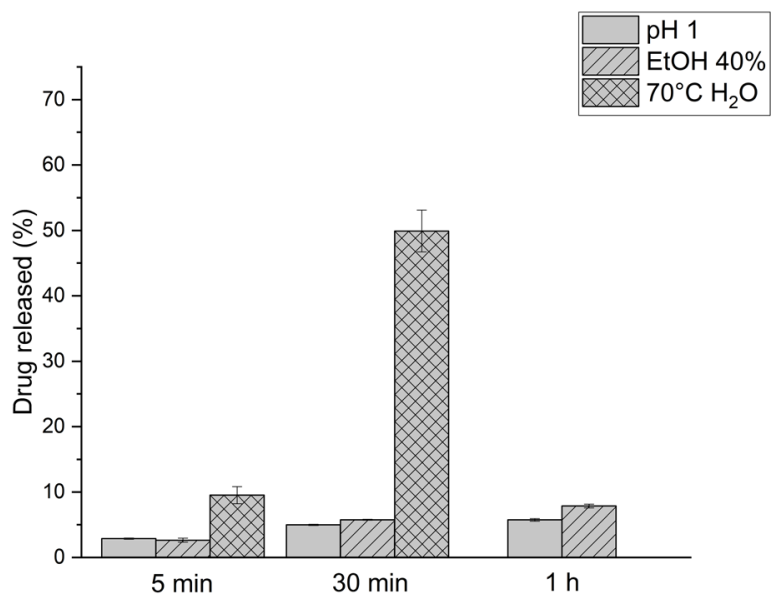

Fig. 4. Abuse deterrent properties for geopolymer in three different media, $n=3$.

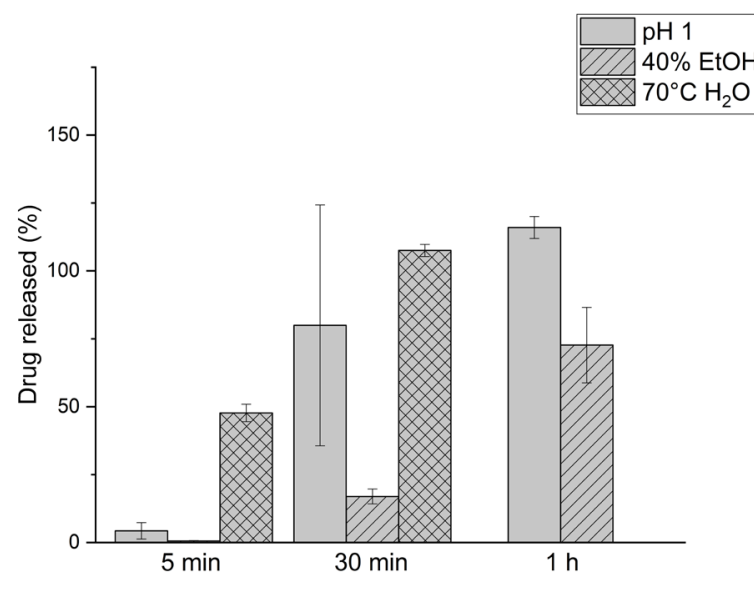

Fig. 5. Abuse deterrent properties for Stilnoct $\AA$ tablets in three different media, $n=3$.

Pharmacokinetic analysis of the collected data demonstrated that immediate-release tablet administration (group 1) generated much higher values for $\mathrm{C}_{\max }$ and $\mathrm{AUC}$ compared with geopolymer pellets administration (group 2) (Table III). On the other hand, the geopolymer pellet formulation prolonged the time of drug release.

Clinical signs were normal for all dogs at all time points investigated. However, dog 2 (geopolymer pellets, group 2) vomited 30 min after administration. The number of vomited pellets was 12 compared with 64 pellets in each capsule, which is $20 \%$ of the administered dose. Since the dog was already administered with the majority of the dose, the decision of the veterinarian responsible and the study director was not to administer the dog with an additional capsule.

\section{DISCUSSION}

The abuse-deterrent properties were investigated in nonsink conditions in order to mimic some extraction methods which are available to abusers (6). After termination of the tests, approximately $10 \%$ zolpidem was released from the geopolymer pellets in both $\mathrm{pH} 1$ and $40 \%$ ethanol, while almost $50 \%$ zolpidem was released when $70^{\circ} \mathrm{C}$ water was used as the solvent (Fig. 4). Eudragit starts dissolving above $\mathrm{pH}$ 5.5, which can explain the higher release of zolpidem in water compared with acidic conditions. All geopolymer pellets were intact after the tests. Stilnoct ${ }^{\circledR}$ tablets completely disintegrated within 30 min in $70^{\circ} \mathrm{C}$ water and after $1 \mathrm{~h}$ in $\mathrm{pH} 1$. A variation in the 30 -min samples at $\mathrm{pH} 1$ could be observed. This might be due to the fast disintegration of the tablets in a small volume resulting in a higher risk of uneven sampling. Overall the geopolymer pellets showed better abuse-deterrent properties than the immediaterelease tablet.

Table III. Pharmacokinetic parameters for both groups, including average with standard deviations.

\begin{tabular}{|c|c|c|c|c|c|c|c|c|c|c|}
\hline & \multicolumn{5}{|c|}{ Group 1 , zolpidem IR tablets } & \multicolumn{5}{|c|}{ Group 2, zolpidem pellets } \\
\hline & D1 & D2 & D3 & D4 & Average & D1 & D2 & D3 & D4 & Average \\
\hline $\mathrm{C}_{\max }(\mathrm{ng} / \mathrm{mL})$ & 23.7 & 16.7 & ND & 22.9 & $21.1 \pm 3.8$ & 1.5 & 0.1 & ND & 1.0 & $0.9 \pm 0.7$ \\
\hline $\mathrm{T}_{\max }(\mathrm{h})$ & 0.5 & 1 & ND & 0.5 & $0.7 \pm 0.3$ & 6.0 & 1 & ND & 1.0 & $2.5 \pm 3.0$ \\
\hline$t_{1 / 2 \text { elimination }}(\mathrm{h})$ & 0.2 & 0.4 & ND & 0.4 & $0.3 \pm 0.1$ & 0.1 & NC & NC & 0.5 & $0.3 \pm 0.3$ \\
\hline $\mathrm{AUC}_{24 \mathrm{~h}}(\mathrm{~h} * \mathrm{ng} / \mathrm{mL})$ & 43.7 & 30.4 & ND & 26.5 & $33.5 \pm 9.0$ & 13.1 & 0.1 & 0.0 & 2.9 & $4.0 \pm 6.2$ \\
\hline
\end{tabular}

D: dog; IR: immediate release; NC: not calculated; ND: not detected. 

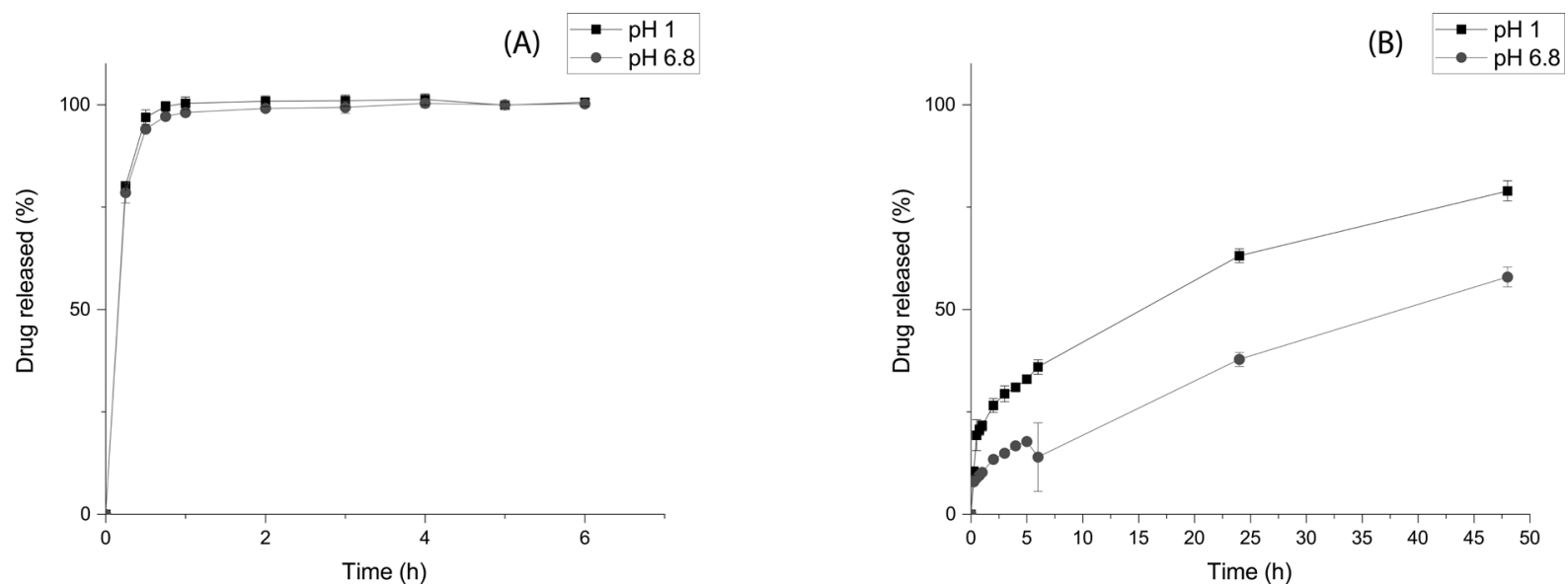

Fig. 6. Zolpidem tartrate release from: (A) Stilnoct ${ }^{\circledR}$ tablets and (B) geopolymer pellets, $n=3$. The dissolution test was performed under $24 \mathrm{~h}$ in $\mathrm{pH} 1(\square)$ and $\mathrm{pH} 6.8(\bullet)$. The error bars represent the standard deviation at each time point.

In vitro data for the geopolymer pellets predicted a prolonged release for $24 \mathrm{~h}$ (Fig. 6B) but in vivo data showed that the plasma concentration started to decrease after $1 \mathrm{~h}$ for dog 4 and $6 \mathrm{~h}$ for dog 1 (group 2) (Fig. 7B). This difference in $T_{\max }$ for dogs 1 and 4 can be explained by the transit time. The gastrointestinal tract in beagle dogs has been investigated in a previous study, showing that there is significant variability in $\mathrm{pH}$ profiles and transit times (20). For example, the median gastric transit time is $1 \mathrm{~h}$, but with a standard deviation (SD) of $6 \mathrm{~h}$; and the median total transit time is $18 \mathrm{~h}$ with an SD of $10 \mathrm{~h}$. The drug release profile in Fig. 6 demonstrates that the drug release is somewhat faster at gastric pH 1 than intestinal pH 6.8. Dog 4 may have had a longer gastric transit time but a shorter total transit time than dog 1 , causing the shorter $\mathrm{T}_{\max }$ for dog 4 compared with dog 1 . Thus, the low uptake of zolpidem from geopolymer pellets, still demonstrates a controlled-release profile compared with the instant release tablets.

As mentioned previously, dog 2 (geopolymer pellets, group 2) vomited $20 \%$ of the dose after administration. The lack of $20 \%$ of the dose may have contributed to the low uptake shown for dog 2, with low plasma values below the LLOQ. For the dogs in group 2 (geopolymer pellets), the lack of detection suggests that the drug release was most likely low as a consequence of the controlled-release properties of the geopolymer pellets, but for the dog in group 1 (Stilnoct ${ }^{\circledR}$ immediate-release tablets), the lack of absorption has no rational explanation.

To the best of the authors' knowledge, this is the first time a geopolymer has been tested as an oral formulation in vivo. In this study, we present preliminary in vivo data for geopolymer as an oral formulation showing the feasibility of delivering zolpidem by prolonged release from an abuse-deterrent formulation. Furthermore, previous studies have shown that no significant amount of aluminium leakage occurs after dissolution at $\mathrm{pH} 1$ and $\mathrm{pH} 6.8$ (13).

\section{CONCLUSIONS}

Abuse-deterrent properties were investigated for both Stilnoct ${ }^{\circledR}$ tablets and geopolymer pellets, where geopolymer pellets showed significantly lower drug release. The pharmacokinetics of zolpidem tartrate were examined in dogs after a single administration of tablets or pellets. Oral administration of zolpidem tartrate in geopolymer pellets demonstrated a controlled-release plasma profile opposite to the immediaterelease tablets. However, the geopolymer pellet exhibited low plasma levels and exposure, which can be explained by the prolonged drug release, as demonstrated in in vitro studies. Both groups show the same half-life $\left(t_{1 / 2}=0.3 \mathrm{~h}\right)$. No significant adverse clinical signs were seen in the dogs after oral administration of
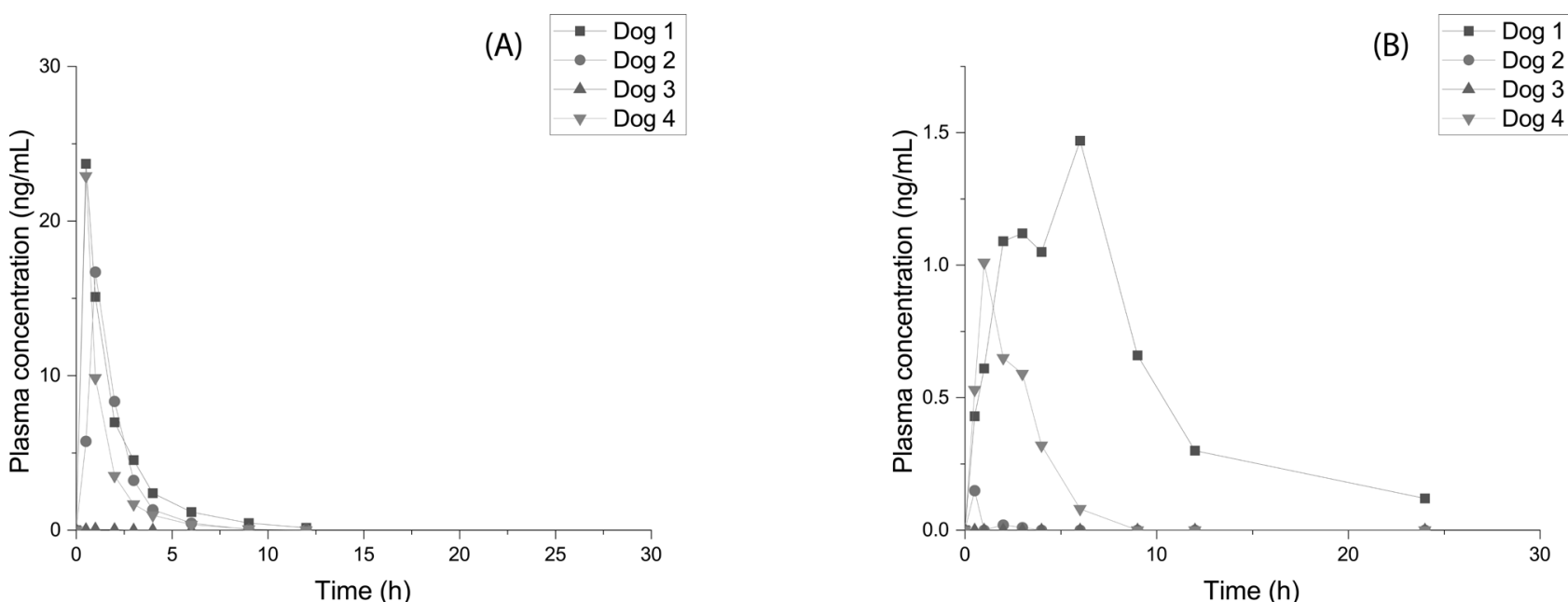

Time (h)

Fig. 7. Zolpidem tartrate plasma profiles after oral administration to dogs. (A) Group 1 received 5 mg zolpidem tartrate IR tablets and (B) Group 2 received $6 \mathrm{mg}$ zolpidem tartrate geopolymer pellets 
the two test items. To conclude, it was possible to safely deliver zolpidem from a geopolymer abuse-deterrent formulation.

\section{Conflicts of interest}

Engqvist is a board member and shareholder in Emplicure $A B$ - a drug delivery company.

\section{Acknowledgement}

Funding from the faculty is gratefully acknowledged. The authors would like to thank SPM Biocameltec for their contribution. The authors would also like to acknowledge Susanne Bredenberg and Ulrika Espefält Westin, both at Emplicure $A B$, for their contribution to the project.

\section{References}

1. Minozzi S, Amato L, Davoli M. Development of dependence following treatment with opioid analgesics for pain relief: a systematic review. Addiction. 2013;108(4):688-698.

2. Epidemic: Responding to America's Prescription Drug Abuse Crisis [Internet]. 2011. Available from: http://publications.iowa. gov/12965/1/NationalRxAbusePlan2011.pdf

3. Hedegaard $H$, Warner M, Miniño AM. Drug Overdose Deaths in the United States, 1999-2016. NCHS Data Brief. 2017;Dec(294):1-8.

4. Scholl L. Drug and Opioid-Involved Overdose Deaths - United States, 2013-2017. MMWR Morb Mortal Wkly Rep. 2018;67(5152):1419-1427.

5. Assessment of Abuse Potential of Drugs - Guidance for Industry [Internet]. U.S. Food and Drug Administration. 2017. Available from: https://www.fda.gov/downloads/drugs/guidances/ ucm 198650.pdf

6. Abuse-Deterrent Opioids - Evaluation and Labeling. Guidance for Industry [Internet]. U.S. Food and Drug Administration. 2015. Available from: https://www.fda.gov/downloads/Drugs/ Guidances/UCM334743.pdf

7. Abuse-Deterrent Opioid Analgesics [Internet]. U.S. Food and Drug Administration. 2017. Available from: https://www.fda.gov/Drugs/DrugSafety/ ostmarketDrugSafetyInformationforPatientsandProviders/ ucm600788.htm

8. Bose S, Tarafder S. Calcium phosphate ceramic systems in growth factor and drug delivery for bone tissue engineering: a review. Acta Biomater. 2012;8(4):1401-1421.

9. Cai B, Xia W, Bredenberg S, Li H, Engqvist H. Bioceramic microneedles with flexible and self-swelling substrate. Eur ] Pharm Biopharm. 2015;94:404-410.

10. Cai B, Engqvist $H$, Bredenberg S. Evaluation of the resistance of a geopolymer-based drug delivery system to tampering. Int J Pharm. 2014;465(1-2):169-174.

11. Jämstorp E, Forsgren J, Bredenberg S, Engqvist H, Strømme $M$. Mechanically strong geopolymers offer new possibilities in treatment of chronic pain. J Control Release 2010;146(3):370-377.

12. Ebina Y, Okada S, Hamazaki S, Midorikawa O. Liver, kidney, and central nervous system toxicity of aluminum given intraperitoneally to rats: A multiple-dose subchronic study using aluminum nitrilotriacetate. Toxicol Appl Pharmacol. $1984 ; 75(2): 211-218$.

13. Cai B. Digital Comprehensive Summaries of Uppsala Dissertations from the Faculty of Science and
Technology. 2020. Available from: http://urn.kb.se/ resolve?urn=urn:nbn:se:uu:diva-245031

14. Aguilar F, Autrup H, Barlow S, Castle L, Crebelli R, Dekant W, et al. Safety of aluminium from dietary intake. Scientific Opinion of the Panel on Food Additives, Flavourings, Processing Aids and Food Contact Materials (AFC). EFSA J. 2008;6(7):1-34.

15. Simon V, Cavalu S, Prinz M, Vanea E, Neumann M, Simon $\mathrm{S}$. Albumin adsorption on the surface of iron containing aluminosilicates. Eur Cells Mater. 2008;16(Suppl. 1):55.

16. Martin S, Derrien AC, Oudadesse H, Cathelineau G. Implantation of aluminosilicate / calcium phosphate materials' influence on bone formation in rabbit tibias. Eur Cells Mater. 2002;9:71-72.

17. Forsgren J, Jämstorp E, Bredenberg S, Engqvist H, Strømme M. A ceramic drug delivery vehicle for oral administration of highly potent opioids. J Pharm Sci. 2010;99(1):219-226.

18. Fentanyl citrate | C28H36N2O8 - PubChem [Internet]. Available from: https://pubchem.ncbi.nlm.nih.gov/compound/Fentanylcitrate

19. Zolpidem tartrate | $\mathrm{C} 23 \mathrm{H} 27 \mathrm{~N} 3 \mathrm{O} 7$ - PubChem [Internet]. Available from: https://pubchem.ncbi.nlm.nih.gov/compound/Zolpidemtartrate\#section=Solubility

20. Zou H, Shimizu J, Wanke C, Iordanov VP. Transit and pH in Fasted Beagle Dogs with the IntelliCap System. 2013. Available from: https://api.semanticscholar. org/36bb5132d09eed1244e59fa8b180ed0e52b11874 